\title{
A PILOT EXPLORATION OF SPEECH SOUND DISORDER INTERVENTION DELIVERED BY TELEHEALTH TO SCHOOL-AGE CHILDREN
}

\author{
SUSAN GROGAN-JOHNSON, PHD ${ }^{1}$, RODNEY M. GABEL, PHD², \\ JACQUELYN TAYLOR, MA³, LYNNE E. ROWAN, PHD ${ }^{1}$, ROBIN AlVARES, PHD, ${ }^{1}$ \\ JASON SCHENKER, PHD ${ }^{4}$ \\ ${ }^{1}$ Speech Pathology and Audiology Department, Kent State University, OH \\ 2 BOWLING GREEN STATE UNIVERSITY, BOWLING GREEN, OH \\ 3 PRIVATE PRACTICE, WILMINGTON, NC \\ ${ }^{4}$ Foundations, LEADERSHIP, AND ADMINISTRATION, KENT STATE UNIVERSITY, KenT, OH
}

\section{ABSTRACT}

This article describes a school-based telehealth service delivery model and reports outcomes made by school-age students with speech sound disorders in a rural Ohio school district. Speech therapy using computer-based speech sound intervention materials was provided either by live interactive videoconferencing (telehealth), or conventional side-by-side intervention. Progress was measured using pre- and post-intervention scores on the Goldman Fristoe Test of Articulation-2 (Goldman \& Fristoe, 2002). Students in both service delivery models made significant improvements in speech sound production, with students in the telehealth condition demonstrating greater mastery of their Individual Education Plan (IEP) goals. Live interactive videoconferencing thus appears to be a viable method for delivering intervention for speech sound disorders to children in a rural, public school setting.

Keywords: Telehealth, telerehabilitation, videoconferencing, speech sound disorder, speech therapy, speech-language pathology; E-Helper

\section{INTRODUCTION}

School districts throughout the United States are attempting to deal with the shortage of speech-language pathologists (SLPs) to provide intervention for schoolage children with communication impairments. One proposed solution is the use of telehealth as a service delivery model (American Speech-language Hearing Association [ASHA], 2005). Telehealth is a term commonly used in the fields of speech-language pathology and audiology to refer to a service delivery model in which assessment and intervention services are provided over a telecommunications network (ASHA, 2005).

In an effort to eliminate SLP personnel shortages in the state of Ohio, the Ohio Department of Education (ODE) brought together stakeholders, (i.e., representatives from Ohio's universities with speech-language pathology programs, the Ohio Board of Speech Language Pathology \& Audiology (OBSLPA), Ohio Master's Network Initiatives in Education (OMNIE), Ohio School Speech Pathology Educational Audiology Coalition (OSSPEAC), Ohio Speech Language Hearing Association (OSHLA), and the Ohio Speech Language Pathology and Educational Audiology
Supervisory Network) to form a task force responsible for creating a state-wide initiative. The resulting program consisted of eight initiatives funded by the Ohio Department of Education (Boswell, 2007). One of these initiatives, a pilot telehealth project, provides speechlanguage intervention services to students in rural school districts via live interactive video conferencing.

The purpose of the pilot telehealth project, is to determine if a telehealth service delivery model can be adequately implemented in a public school setting and if children with speech sound disorders make similar amounts of progress in speech-language intervention when they receive services via synchronous interactive video conferencing as compared to a more traditional, side-by-side service delivery model.

Speech sound disorders were selected as the focus of this study because the National Outcomes Measurement Scales K-12 2008 National Data Report indicates that the majority of students who receive speech-language intervention services in the schools have impairments in speech sound production (ASHA, 2008). Approximately $60 \%$ of the average caseload is composed of children with one or two sound errors, and an additional $15 \%$ is 
composed of children with multiple sound speech sound errors. Therefore, 75\% of a typical school based SLP's caseload consists of children with speech sound disorder impairment (ASHA, 2008). These children typically receive intervention services through small group pull-out sessions twice a week for 21-30 minutes (ASHA, 2008). Based on these statistics, we determined that a study of intervention progress for children with speech sound disorders would be of particular interest. In addition, the pull-out service delivery model reported for traditional speech intervention would be similar to the pull-out services provided by our current telehealth pilot project.

\section{PRIOR STUDIES}

While the potential for telehealth to provide access to speech-language intervention services for underserved populations is becoming well recognized (ASHA, 2005; Lewis, Packman, Onslow, Simpson \& Jones, 2008; Polovoy, 2008), there are few telehealth investigations that report actual outcome data from speech-language intervention to children with speech sound disorders and/or language impairment (Lewis, Packman, Onslow, Simpson \& Jones, 2008). Two articles of interest related to the provision of services by telehealth to school-age children in educational settings and revealed project descriptions and satisfaction survey results that generally support the use of telehealth (Forducey, 2006; Madsen \& Shellsey, 2005).

Grogan-Johnson, Alvares, Rowan \& Creaghead (2010) recently reported that school-age children $(\mathrm{N}=34)$ with articulation, language and/or fluency impairments made similar progress via either telehealth or traditional side-byside speech-language intervention. In the first group, 17 children received telehealth intervention for four months and then conventional intervention for four months. In the second group, 17 children received conventional intervention first, followed by four months of telehealth intervention. Progress was measured by pre- and postintervention results on the GFTA-2 (Goldman \& Fristoe, 2002), with no significant difference in pre- and postintervention GFTA-2 scores (Goldman \& Fristoe, 2002) for the two groups. Quarterly progress reports also indicated that students made similar progress during the study in whichever intervention method was used.

Two earlier telehealth studies of childhood speech sound and language disorders also showed promising results. A pilot study comparing the assessment of children with speech sound disorders side-by-side vs. videoconferencing resulted in high levels of agreement in scoring for single word articulation, speech intelligibility, and oral motor tasks between the online and the side-byside SLPs (Waite, Cahill, Theodoros, Busuttin, \& Russell, 2006). Waite, Theodoros, Russell, and Cahill (2010) recently conducted an online assessment of children ages 5 years - 9 years with suspected language impairment using a multimedia presentation of the four core subtests of the Clinical Evaluation of Language Fundamentals4th edition (CELF-4) (Semel, Wiig, \& Secord, 2004). Simultaneous on-line and side-by-side scoring revealed no significant difference between the two service delivery models. The authors concluded that online assessment using a multi-media presentation may be a valid method for assessing language impairment in young school-age children.

The technology utilized in the reviewed studies ranged from using telephones to interactive videoconferencing over an integrated services digital network connection, to a PC-based, desktop videoconferencing system operating over an Internet Protocol (IP) connection used in our earlier research (Grogan-Johnson, et al., 2010). One unique characteristic of our videoconferencing procedure is that application sharing is provided with video and audio sharing throughout the intervention session. During intervention, the student sees and hears the SLP and both can simultaneously access web based activities, software or document files. The use of software or online computer based activities is referred to as computer assisted instruction (CAI).

Computer use to increase instructional effectiveness has been demonstrated across curriculum content areas in the elementary school setting (Christmann \& Badgett, 2003). Proponents of computer assisted technology claim that it increases student motivation and engagement, and thus improves student learning (Van Dusen \& Worthen, 1995). Gierut (1998) concluded that CAI is highly effective because it is structured, supplemental, and enjoyable and can be completed independently by children. Early studies of CAI based articulation therapy (Shriberg, Kwiatkowski and Snyder, 1989, 1990) indicated that elementary age students with articulation impairments benefitted from CAl during sound production practice, in that the CAI enabled them to stabilize newly learned articulatory movements. However, CAl was less effective during the early stages of therapy when students were not consistently able to produce correct target sounds. CAI materials for articulation therapy continue to be developed and implemented with generally successful results as reported in case studies (Masterson, 1995, McGuire, 1995, Ruscello, Yanero \& Ghalichebaf, 1995).

\section{CURRENT PILOT STUDY}

The current pilot study examined whether sound disorder intervention using computer-based intervention materials with kindergarten through sixth grade students is comparable for services delivered via telehealth versus by a side-by-side SLP. A secondary purpose was to determine if a randomized, controlled study comparing the two service delivery models is warranted.

Initial baseline data and testing was conducted from the last week of October through the first week 
of November 2008, and end of the year testing was conducted during the third and fourth weeks of May 2009. However, because each of the students in the project was on an IEP for the entire 2008-2009 academic year, speech and language services were provided from the first full week through the last full week of the school calendar year.

This effort represents a prospective study conducted within the constraints of actual service delivery to students identified with communication impairments within a typical school-based intervention program. The methodology was constrained by the evaluation tools and strategies typically employed in those school settings. Additionally, the small sample size precluded broadbased statistical analysis.

\section{SUBJECTS}

Study participants were recruited from two elementary buildings in a rural Ohio school district participating in the OMNIE/ODE telehealth pilot project. The school district had assigned one elementary building to be staffed by the telehealth SLP, and the second to be staffed by a sideby-side SLP. Since potential experimental participants were identified from each of the elementary buildings, this allowed for a comparison of the efficacy of live and remote speech-language service delivery with the same student population. Prior to their entrance in the project, students with communication impairments were evaluated by a side-by-side SLP who had established Individualized Education Plans (IEP) that specified intervention goals, types, and amount of intervention, and the methodology for monitoring progress.

Students eligible to participate were first identified from the caseload of students in the elementary school with telehealth intervention services. The inclusion requirements were: students in kindergarten through sixth grade; communication impairment based on the definitions of disability under the Individuals with Disabilities Education Act of 2004 (IDEA 2004); and a current Individual Education Plan (IEP) with goals for remediating a speech sound disorder. Excluded were: students with a diagnosis of autism, pervasive developmental disorder, cognitive deficits or severe emotional disturbance and visual and hearing impairments severe enough to meet identification criteria as a student with a visual or hearing impairment under the IDEA 2004 (IDEA 2004). Students learning English as a second language were also excluded from this study.

Based on the ages, grade levels, and types of sound errors represented in the first group of students (i.e., the elementary school where telehealth intervention services were provided), the SLP who provided side-byside services was asked to identify potential participants who would be similar in age, grade, and sound errors for inclusion in the study. Two groups of students were thus identified: Group 1 was to receive speech intervention by telehealth and Group 2, side-by-side intervention.

A total of 13 students, kindergarten through sixth grade, participated in the project. Ages ranged between 6 and 11 years; 11 were male and 2 were female. Table 1 contains identifying information about the participants. Fifteen students were initially identified for the study, however, two students from the side-by-side group moved from the school district during the school year. All of the participants had a speech sound impairment. Three students also had impairment in expressive language skills and received an additional intervention session weekly to remediate the language impairment.

Before data collection was initiated, parents signed a permission form and children provided verbal consent to the project as outlined in the Speech-language Pathology Telehealth Pilot Project approved by the Kent State University Institutional Review Board.

\section{Table 1. Subject description and intervention summary.}

* Students with articulation and expressive language impairment. Each received an additional 20 minute

\begin{tabular}{|c|c|c|c|c|c|c|c|c|}
\hline SS & Gender & Age & Grade & $\begin{array}{l}\text { Target sounds } \\
\text { identified in child's IEP }\end{array}$ & $\begin{array}{l}\text { GFTA-2 } \\
(\mathrm{F}) * *\end{array}$ & $\begin{array}{l}\text { GFTA-2 } \\
(\mathrm{S}) * * *\end{array}$ & $\begin{array}{l}\# \\
\text { Sessions }\end{array}$ & $\begin{array}{l}\text { Intervention } \\
\text { Schedule }\end{array}$ \\
\hline \multicolumn{9}{|c|}{ Telehealth Group } \\
\hline 1 & $\mathrm{M}$ & $11 ; 0$ & 4 & /s/blends, /t,,,$t 5 /$ & 62 & 69 & $27 / 37$ & $20 \mathrm{~min} /$ ind. \\
\hline 2 & M & $10 ; 5$ & 4 & /s/blends, /s,z,v, $, \mathrm{t}, \mathrm{\ominus} / \mathrm{A}$ & 78 & 99 & $27 / 34$ & $20 \mathrm{~min} /$ ind. \\
\hline 3 & $\mathrm{~F}$ & $9 ; 4$ & 3 & /s/blends, /s,e,k,g,l/ & 40 & 67 & $48 / 70$ & 40min/ind. \\
\hline 4 & M & $7 ; 1$ & 2 & $\left./ s, z, r, \int, t\right\}, \theta /$ & 98 & 108 & $24 / 36$ & $20 \mathrm{~min} /$ ind. \\
\hline 5 & $\mathrm{M}$ & $8 ; 8$ & 2 & /s.r/ blends, /s,r, $,{ }^{\prime}, \theta, /$ & 85 & 106 & $28 / 37$ & $20 \mathrm{~min} /$ ind. \\
\hline 6 & $\mathrm{M}$ & $11 ; 11$ & 6 & $/ \mathrm{s}, 1 /$ blends, $/ \mathrm{r}, \int, \mathrm{t} f, \Theta /$ & 92 & 104 & $32 / 37$ & $20 \mathrm{~min} /$ ind. \\
\hline 7 & $\mathrm{M}$ & $8 ; 6$ & 3 & $/ \int, \mathrm{t}^{\prime}, \theta, \mathrm{r} /$ & 54 & 70 & $32 / 37$ & $20 \mathrm{~min} /$ ind \\
\hline \multicolumn{9}{|c|}{ Side-by-Side Group } \\
\hline 1 & $\mathrm{~F}^{*}$ & $6 ; 3$ & $\mathrm{~K}$ & $/ \theta, \mathrm{s}, 1 /$ & 88 & 90 & $22 / 28$ & $20 \mathrm{~min} /$ ind \\
\hline 2 & $M^{*}$ & $6 ; 9$ & 1 & /f,v,s,l/ & 52 & 61 & $28 / 33$ & $20 \mathrm{~min} /$ ind \\
\hline 3 & M & $8 ; 4$ & 2 & $/ s, z, \int, t /$ & 65 & 69 & $25 / 33$ & $20 \mathrm{~min} /$ ind. \\
\hline 4 & $\mathrm{M}$ & $8 ; 5$ & 2 & $/ \mathrm{s}, \mathrm{z}, \mathrm{r} /$ & 101 & 106 & $24 / 33$ & $20 \mathrm{~min} / \mathrm{ind}$. \\
\hline 5 & $\mathrm{M}^{*}$ & $9 ; 8$ & 3 & $/ \theta, \mathrm{r} /$ & 103 & 105 & $21 / 33$ & $20 \mathrm{~min} / \mathrm{ind}$ \\
\hline 6 & M & $10 ; 9$ & 5 & $/ \mathrm{r} /$ blends, $/ \mathrm{r}, \Theta /$ & 99 & 105 & $25 / 33$ & $20 \mathrm{~min} /$ ind. \\
\hline
\end{tabular}

session weekly to focus on language intervention.

** Individual standard scores for Goldman Fristoe Test of Articulation-2 (Goldman \& Fristoe, 2002) administered in fall, 2008.

*** Individual standard scores for Goldman Fristoe Test of Articulation-2 (Goldman \& Fristoe, 2002) administered in spring, 2009 . 


\section{PERSONNEL}

\section{SPEECH-LAnguage PATHOlogists}

Intervention for the telehealth group was provided by a Master's level SLP who also held the Certificate of Clinical Competence (CCC) issued by the American Speechlanguage Hearing Association (ASHA). Intervention for the side-by-side participants was provided by an OMNIE SLP intern who had completed their academic graduate training program and was licensed by the Ohio Board of Speech-Language Pathology and Audiology to be employed in public school districts with supervision for one year prior to traditional employment. Both SLPS had experience with administering the Goldman-Fristoe Test of Articulation-2 (Goldman \& Fristoe, 2002) as well as classroom instruction and clinical practice using a traditional articulation intervention approach (Secord, 1989) to intervene with children with speech sound disorders. In preparation for this project, the SLPs were asked to review the traditional approach to speech sound intervention in a book chapter related to the topic (Secord, 1989) and to identify the specific components of the traditional approach that would be utilized with each student in the project.

\section{E-HELPER}

An e-Helper, an adult who met the school district requirements for a classroom assistant, was present during the intervention sessions to ensure that any technology glitches were corrected as well as to provide adult supervision. During a one-hour individual session, the e-Helper was trained by the first author on how to use the telehealth equipment, basic trouble-shooting strategies, e-Helper responsibilities, and guidelines for maintaining confidentiality.

\section{SOFTWARE}

The software selected for use in the current study for both therapy conditions (i.e., telehealth and side-byside), was TinyEYE Speech Therapy Software (Sutton \& Brick, 2005). This subscription software is available online (http://www.TinyEYE.com), and provides a collection of therapy materials that includes on-line interactive speech sound disorder drill activities, games (e.g., Go Fish, memory games), and visual reinforcement activities (e.g. dress a character, add petals to a flower) that can be individualized by the SLP. The software allows for data collection, progress monitoring, and report writing. These games and reinforcements replaced the speech sound drill cards and table top activities typically utilized in therapy. The software provides continuous audio and visual contact between the SLP and student and allows for collaborative sharing of the speech sound online activity, as directed by the SLP. We also considered using software programs for therapy activities and reinforcement. While the software programs ran at an acceptable speed in the side-by-side condition, the software programs with videoconferencing software operated at such a slow speed as to make their use prohibitive for intervention sessions.

\section{EQUIPMENT}

Technology utilized in the telehealth condition at the school site included: Dell Inspiron XPS 410 desktop computer with Microsoft Windows XP operating system; 19" widescreen flat panel display; Logitech Quick Cam Orbit MP Color Web Camera with built in microphone, and accompanying headset. An additional Logitech headset and Radio Shack $®$ brand audio splitter were purchased so that an e-Helper could listen to intervention sessions as needed. Technology utilized at the Kent State University site included: Dell Optiplex 755 desk top computer with Windows XP operating system; 22" widescreen flat panel display; Logitech Quick Cam Orbit MP Color Web Camera with built in microphone and accompanying headset.

The video conferencing between Kent State University and the rural Ohio school district was through a $10 \mathrm{Mb}$ switched connection through Kent State University's Optical Connection-3 to the Ohio Academic Resources Network (OARnet) to reach the T1 connection at the distance sites. The OARnet is an integrated technology infrastructure that provides support and services to all academic institutions including $\mathrm{K}-12$ schools in Ohio. Student privacy was maintained through 128-bit AES internet signal encryption which meets Federal Information Processing Standards (FIPS) and is HIPPA compliant.

\section{INTERVENTION}

The intervention services provided followed the goals and objectives and amount of time listed on each child's IEP. The intervention schedule is detailed in Table 1.

The SLPs implemented a traditional approach to speech sound disorder intervention, and included the stages of auditory discrimination, sound production training, and sound stabilization, followed by sound transfer, carryover, and maintenance (Secord, 1989). Intervention sessions in both service delivery models followed a session format which included: review of session objectives, intervention using TinyEye Speech Therapy Software (Sutton \& Bricker, 2005), and review of goals and progress at the end of each session. 
Therapy sessions for both service delivery models were conducted in private offices located in the respective elementary school buildings. Each office was equipped with a desk and chairs as well as the computer and the associated equipment described above. Students were escorted to and from telehealth intervention sessions by the e-Helper. The e-Helper did not provide specific cueing, reinforcement, or in any way contribute to the actual intervention process. During all telehealth intervention sessions the students maintained visual and audio contact with the SLP at all times, and the SLP remained in control of the TinyEye Speech Therapy Software (Sutton \& Bricker, 2005). In both service delivery models the SLP provided all instruction including cues, feedback and reinforcement related to speech sound production.

\section{MEASURES OF PROGRESS}

Multiple measures of student progress were assessed during the project: 1) pre- and post-intervention results on the Goldman-Fristoe Test of Articulation-2 (GFTA2) (Goldman \& Fristoe, 2002); 2) comparison of preintervention baselines for targeted speech sounds with production levels at the completion of intervention; and, 3) comparison of amount of change reported on quarterly progress reports. These were selected because they represent typical measures of progress/performance for services delivered in the public school setting and allow for the direct comparison of services delivered in the two conditions identified for this study.

To determine the reliability of the GFTA-2 results, all of the test protocols from pre-and post-intervention were reviewed by the principal investigator. The phonetic transcriptions were compared against the recorded scores and reported test results. This review resulted in $100 \%$ agreement with the recorded scores and reported test results.

\section{RESULTS}

There was no significant age difference between the two groups at the start of intervention $(z=-1.43, p=.153)$. The mean of the side-by-side group was 100.33 months (S.D. 20.41) and the mean of the telehealth group was 114.71 months (S.D. 19.88). Comparison of session length and percentage of session attendance for the groups is contained in Table 2 and revealed no significant difference $(z=-.421, p=.710)$.

\section{Table 2. Comparison of session length and percentage of sessions completed.}

\begin{tabular}{lll}
\hline Group & $\begin{array}{l}\text { Mean length } \\
\text { of sessions } \\
\text { (in minutes) }\end{array}$ & $\begin{array}{l}\text { Percentage } \\
\text { of sessions } \\
\text { completed }\end{array}$ \\
\hline Telehealth & 22.9 (range 20-40) & $76 \%$ \\
Side-by-Side & $20($ range 20) & $75 \%$
\end{tabular}

The first measure of student progress was a comparison of results on the GFTA-2 (Goldman \& Fristoe, 2002) which was administered pre- and post-intervention. Table 3 provides mean test scores and standard deviations for the two groups.

\section{Table 3. Description of group GFTA-2 test results.}

\begin{tabular}{lllll}
\hline Group & $\begin{array}{l}\text { M } \\
\text { Fall* }\end{array}$ & SD & $\begin{array}{l}\text { M } \\
\text { Spring** }\end{array}$ & SD \\
Telehealth & 72.71 & 21.31 & 89.00 & 19.24 \\
Side-by-Side & 84.67 & 21.32 & 89.33 & 19.93 \\
\hline
\end{tabular}

\footnotetext{
* Fall administration of GFTA-2 (Goldman \& Fristoe, 2002) ** Spring administration of GFTA-2 (Goldman \& Fristoe, 2002)
}

Analysis of the results using the Mann-Whitney $U$ test revealed no significant difference between the two groups on the pre-test $(z=-.256, p=.805)$ and no significant difference between the two groups on the post-test ( $z$ $=-.257, p=.805$ ). Across both groups of participants there was a significant improvement in performance as measured by the Wilcoxon Signed-Rank Test $(z=$ $-2.449, p=.014$ ). Further analysis was conducted by subtracting the pre-test scores from the post-test scores and comparing the two groups on this difference score to determine which group had the larger amount of change. No significant difference was found between the groups ( $\mathrm{z}$ $=-.704, p=.535$ ).

It was also of interest to investigate whether the difference in test scores from pre- to post-test was more than would be expected given the standard error of measurement (SEM) of the GFTA-2 (Goldman \& Fristoe, 2002). The average SEM of the GFTA-2 across all ages is 3.0 for females, and 3.7 for males. The difference between the telehealth and the side-by-side group was -4.5 , 
which exceeds the SEM in absolute value. Investigating by group reveals the difference was -5.29 for the sideby-side group, and -3.71 for telehealth group. These results suggest that the participants made significant improvements in their articulation skills as measured by the GFTA-2 (Goldman \& Fristoe, 2002).

It must be noted that interpretation of standard scores measuring articulation skills is challenging because articulation ability is not normally distributed within the general population as are other skills (e.g., vocabulary) measured with standard scores. Moreover, the distribution of speech sound errors across age levels is skewed and does not represent a normal distribution at most ages (Goldman \& Fristoe, 2002). Percentile rankings could be utilized to demonstrate change in performance. However, percentiles are ordinal data that cannot be arithmetically manipulated. As a result, we utilized the standard scores from the GFTA-2 (Goldman \& Fristoe, 2002) and gathered additional measures of progress to establish a decision regarding progress in intervention. This is a method of evaluating progress in intervention that is typically used in the public school setting.

The second measure of progress was a comparison of pre-intervention baselines for targeted speech sounds with speech sound production levels at the completion of intervention. Data was collected for all speech sounds identified on each child's IEP at the start and completion of the project. To collect the baseline data, the SLPs showed each student ten color pictures representing words containing their target sound in the initial, medial or final position of the word. The pictures and a written script of instructions were provided to each SLP. Students were shown the pictures and asked to name them. If the student did not recognize the picture the SLP named the picture and asked the student to repeat the name. To collect baseline information for target sounds in phrases, the students were asked to use a carrier phrase (i.e., "It's "). To collect baseline for sentences students were asked to say standardized sentences (e.g., "This is a ____.". "Here is a ______."). Responses were scored correct if the student produced the word correctly or spontaneously self corrected his/her production. Responses were then tallied and converted to percentage correct scores.

When the initial baseline data were collected some of the students obtained scores of $100 \%$ for selected sounds. These sounds were not targeted in intervention and are not included in the baseline tables for the two groups (see Tables 4 \& 5). One exception is participant 6 in the side-by-side therapy group. This participant achieved baseline scores of $100 \%$ on $/ r$, unvoiced th/ and $/ r / /$ blend words, but no other baseline or post-intervention data for targeted sounds such as production of the target sounds in phrases or sentences were available.
Table 4. Telehealth group baseline and post-intervention production levels for target sounds.

\begin{tabular}{|c|c|c|c|}
\hline Student & Phoneme/position/level & Fall* & Spring* \\
\hline \multirow[t]{11}{*}{1} & $/ \int / 1$ words & 80 & 90 \\
\hline & $/ \int / 1 \mathrm{I}$ words in sentences & 10 & 50 \\
\hline & $/[/ \mathrm{m}$ words & 40 & 90 \\
\hline & $/ \int / \mathrm{m}$ words in sentences & 10 & 60 \\
\hline & $/ \int / \mathrm{f}$ words & 20 & 100 \\
\hline & $/ \int / f$ words in sentences & 10 & 80 \\
\hline & $/ \mathrm{s} / \mathrm{I}$ blends in words & 50 & 80 \\
\hline & /s/I blend words in sentences & 40 & 60 \\
\hline & $/ \Theta / I$ words in sentences & 20 & 30 \\
\hline & $/ \Theta / m$ words in sentences & 0 & 30 \\
\hline & $/ \mathrm{e} / \mathrm{f}$ words in sentences & 0 & 90 \\
\hline \multirow[t]{7}{*}{2} & $/ \int / 1 \mathrm{I}$ words & 10 & 60 \\
\hline & $/ \int / f$ words & 70 & 80 \\
\hline & words & 80 & 100 \\
\hline & $/ \Theta / I$ words in sentences & 40 & 70 \\
\hline & $/ \theta / \mathrm{m}$ words in sentences & 40 & 60 \\
\hline & $/ \mathrm{e} / \mathrm{f}$ words in sentences & 50 & 90 \\
\hline & $/ \mathrm{s} / \mathrm{I}$ blend words in sentences & 80 & 100 \\
\hline \multirow[t]{5}{*}{3} & $/ e^{/ I}$ words & 10 & 100 \\
\hline & $/ \Theta / I$ words in sentences & 0 & 100 \\
\hline & $/ \mathrm{e}^{/ \mathrm{m}}$ words & 70 & 100 \\
\hline & $/ \mathrm{e} / \mathrm{m}$ words in sentences & 0 & 100 \\
\hline & $/ \theta^{\mathrm{f}}$ words & 0 & 90 \\
\hline \multirow[t]{8}{*}{5} & $/ \int / 1$, words & 10 & 100 \\
\hline & $/ \int / 1 \mathrm{l}$ words in sentences & 0 & 100 \\
\hline & $/ \mathrm{J} / \mathrm{m}$ words & 10 & 100 \\
\hline & $/ \int /{ }^{f}$ words & 0 & 100 \\
\hline & $/ \int / \mathrm{f}$ words in sentences & 0 & 100 \\
\hline & $/ \theta^{/ I}$ in conversation & 80 & 100 \\
\hline & $/ \mathrm{e} / \mathrm{m}$ in conversation & 10 & 100 \\
\hline & $/ e / f$ in conversation & 70 & 100 \\
\hline \multirow[t]{7}{*}{6} & $/ \int / 1$, in conversation & 80 & 100 \\
\hline & $/ \mathrm{J} / \mathrm{m}$ in conversation & 80 & 90 \\
\hline & $/ \int / \mathrm{f}$ in conversation & 80 & 100 \\
\hline & $/ \mathrm{t} / / 1$ in conversation & 70 & 100 \\
\hline & $/ \mathrm{t} / \mathrm{m}$ in conversation & 80 & 100 \\
\hline & $/ \Theta / \mathrm{m}$ in conversation & 50 & 100 \\
\hline & /r / I words & 70 & 100 \\
\hline \multirow[t]{8}{*}{7} & $/ \int / 1 / 1$ words & 40 & 100 \\
\hline & $/ / /{ }^{f}$ words & 60 & 70 \\
\hline & $/ \mathrm{t} / \mathrm{I}$ words & 40 & 70 \\
\hline & $/ t / 5 / f$ words & 60 & 60 \\
\hline & $/ \Theta / \mathrm{I}$ words in sentences & 60 & 100 \\
\hline & $/ \theta / \mathrm{m}$ words in sentences & 30 & 50 \\
\hline & $/ \Theta / f$ words in sentences & 20 & 80 \\
\hline & $/ \mathrm{r} / \mathrm{I}$ words & 0 & 40 \\
\hline
\end{tabular}


Table 5. Side-by-side group baseline and post-intervention percent correct data levels for target sounds.

\begin{tabular}{|c|l|l|l|}
\hline Subject & Phoneme/position/level & Fall* & Spring** \\
\hline 1 & $/ \Theta / I$ & 30 & 30 \\
\hline & $/ \mathrm{s} /{ }^{\mathrm{I}}$ words & 40 & 70 \\
\hline & $/ 1 /{ }^{\mathrm{I}}$ words & no baseline & 70 \\
\hline 2 & $/ \mathrm{v} / \mathrm{I}$ words & 20 & 90 \\
\hline & $/ \mathrm{s} /{ }^{\mathrm{I}}$ words & 70 & 100 \\
\hline & $/ 1 /{ }^{\mathrm{I}}$ words & no baseline & 90 \\
\hline 3 & $/ \mathrm{s} /{ }^{\mathrm{I}}$ words & 30 & 70 \\
\hline & $/ \mathrm{z} / \mathrm{I}$ words & 50 & 80 \\
\hline & $/ /{ }^{I}$ words & 50 & 40 \\
\hline & $/ \mathrm{t} /{ }^{I}$ words & 0 & 30 \\
\hline 4 & $/ \mathrm{s} / \mathrm{m}, \mathrm{f}$ words in conversation & no baseline & no data \\
\hline & $/ \mathrm{z} / \mathrm{I}, \mathrm{m}, \mathrm{f}$ words in conversation & no baseline & no data \\
\hline 5 & $/ \Theta / \mathrm{I}, \mathrm{m}, \mathrm{f}$ words in conversation & no baseline & no data \\
\hline 6 & no data & no data & no data \\
\hline & & & \\
\hline
\end{tabular}

* Fall baseline

** Spring post-intervention

The baseline and post-intervention data were collected to provide a description of student performance as well as a measure of progress in intervention. SLPs typically collect this type of data at the start of intervention and periodically throughout the course of the school year as a measure of a student's progress towards meeting their individual IEP goals. As such, they represent progress in correctly producing specific phonemes and may more closely reflect the progress a student is making in achieving their specific intervention goals. Each of the children in the project had multiple baselines. To analyze these results, we looked for patterns of performance among and between the two groups. There were a total of 70 baselines targeted in intervention for all of the children in the study. There were 57 baselines collected for the students in the telehealth group resulting in a mean of 8.14 baselines per student ( 7 students), and there was an average of 2.6 baselines per student in the side-by-side group (13 baselines/5 students). Seven of the 70 baselines were eliminated from further analysis as data was missing from either the fall or spring data collections. Table 6 provides an overview of the patterns of change for the baselines by treatment group. Results suggest that both groups made similar amounts of progress as measured by change in speech sound production from baseline to the completion of intervention.

\section{Table 6. Comparison of performance from baseline to post-intervention for both participant groups.}

\begin{tabular}{llll}
\hline Group & $\begin{array}{l}\text { Improved } \\
\text { baselines }\end{array}$ & $\begin{array}{l}\text { Unchanged } \\
\text { baselines }\end{array}$ & $\begin{array}{l}\text { Decreased } \\
\text { baselines }\end{array}$ \\
Telepractice & $98 \%(54 / 55)$ & $2 \%(1 / 55)$ & 0 \\
Side-by-Side & $95 \%(6 / 8)$ & $12.5 \%(1 / 8)$ & $12.5 \%(1 / 8)$ \\
\hline
\end{tabular}

The final data collected were the results provided on quarterly progress reports. Quarterly progress reports measure student performance on IEP objectives by assigning them to one of the following categories: Mastered, Making Adequate Progress, Making Limited Progress, Making No Progress, and Not Introduced. Definitions for each of these progress indicators are contained in Table 7.

\section{Table 7. Definitions of quarterly progress report indicators.}

\section{Mastered Student has met or exceeded the benchmark/goal.}

Not Introduced Benchmark has not been targeted during reporting period. Clinician may have base lined this target during the reporting period but target behavior has not been introduced into therapy.

\section{Adequate Progress \\ With varying levels of clinician scaffolding and/or access to compensatory strategies, the student is performing target behavior above baseline levels. Student is expected to achieve the goal/benchmark within the IEP timeframe.}
Limited Progress
With maximum clinician cueing/scaffolding and/or consistent use of compensatory strategies the student is able to inconsistently perform the target behavior above baseline levels. Improved performance may not be maintained across sessions.

No Progress
Performance compared to baseline has not changed. Student may occasionally demonstrate improvement over baseline levels but student does not maintain performance across sessions OR student is not responding to clinician scaffolding/access to compensatory strategies. 
As is typical in the public school setting, the SLPs involved in the project were asked to rate participants' performance using these student performance indicators and descriptions. Additional observation notes or comments could also be provided at the SLP's discretion. Quarterly progress report results, while based on subjective clinic ratings, were selected to measure student progress as they are the most frequently utilized tool in the public school setting to measure progress towards meeting annual IEP goals and objectives. Quarterly progress report results are typically utilized to identify year-end progress and aid in establishing IEP goals for the next academic year. A description of results from comparison of fourth quarter progress reports for the two intervention groups is contained in Table 8.

A Chi-Square test was used to determine whether the frequency of mastering IEP goals differed between the two groups. The result was significant $\left(X^{2}=7.36, d f=2, p\right.$ $=.025)$ as more students than expected (84\%) mastered IEP goals in the telehealth group as compared with $46 \%$ who mastered IEP goals in the side-by-side group.
Two other measures of progress frequently utilized in public school settings were also employed to collect data on students' performance in the two service delivery models. Those two methods included comparison of baseline and post-intervention speech sound production levels and summary of progress as rated on quarterly progress reports. The comparison of baseline and postintervention speech sound production levels indicated similar patterns of performance among the students in the two service delivery models. These measures of performance reflect progress towards correctly producing specific speech sounds identified on each student's IEP. These production levels were then utilized to complete the quarterly progress reports.

As noted previously, quarterly progress reports were utilized as a measure of student progress because they are widely used to report student progress towards meeting annual IEP goals and objectives. Assignments of amount of progress made on IEP goals are based on data collected during intervention sessions, and the clinician's judgment that the results obtained reflect a specific

designation of progress. Progress report results may be influenced by the experience of Table 8. Comparison of fourth quarter progress report results by intervention group.

\begin{tabular}{|c|c|c|c|c|c|}
\hline Group & $\begin{array}{l}\text { IEP objectives } \\
\text { Mastered }\end{array}$ & $\begin{array}{l}\text { IEP objectives } \\
\text { Adequate } \\
\text { Progress }\end{array}$ & $\begin{array}{l}\text { IEP objectives } \\
\text { Limited Progress }\end{array}$ & $\begin{array}{l}\text { IEP objectives } \\
\text { No Progress }\end{array}$ & $\begin{array}{l}\text { IEP objectives } \\
\text { Not Introduced }\end{array}$ \\
\hline Telepractice & $21 / 25$ (84\%) & $4 / 25$ (16\%) & 0 & 0 & 0 \\
\hline Side by Side & $7 / 15(47 \%)$ & $6 / 15$ (40\%) & 0 & 0 & $2 / 15$ (13\%) \\
\hline
\end{tabular}
the SLP, accuracy of data collected, IEP goal selection, and/or perceived expectations that all students will master their annual IEP goals, and objectives. As such, quarterly progress

\section{DISCUSSION}

This pilot study described how telehealth speech intervention services were provided to students in a rural public school setting from a university setting, and compared the progress made for telehealth versus a sideby-side delivery. The study focused on speech sound disorder intervention using computer based intervention materials in both conditions.

Review of the collected data indicates that for the students who participated in this project, live interactive videoconferencing of speech sound intervention was a sufficiently effective service delivery model to justify further study. Following intervention, students in the telehealth group made significant improvement in speech sound production as measured by change in scores on the GFTA-2 (Goldman \& Fristoe, 2002). This result is similar to the improvement noted in the traditional sideby-side group. report results may not stand alone as a reliable measure of a child's progress. However, when compared with the results of the other progress monitoring measures, the current progress report data corroborates the pattern of performance of the two intervention groups.

The convergence of the results from three measures of student performance provided initial data comparing school-aged students' progress in traditional speech sound intervention delivered via telehealth as compared to a side-by-side speech/language intervention delivery constrain the conclusions that can be deduced and several caveats need to be considered. First, relatively small numbers of participants were included in each treatment group. Also, participants were selected from a population of students who were already receiving intervention, thus random assignment was not possible. Statistical significance testing takes into account sample size, and finding a statistically significant result for change in performance on the GFTA-2 (Goldman \& Fristoe, 2002) with this small sample could be considered more model. The methodological limitations of this trial 
meaningful than obtaining the same value with a much larger sample, where obtaining such a value is much more likely. Researchers attempt to obtain larger sample sizes in order to increase the likelihood that they will obtain statistical significance. While it is important to replicate these findings with a randomly assigned group of participants, it is promising that this initial investigation revealed a positive change in performance for the participants in the telehealth service delivery model.

One of the perceived challenges of the telehealth service delivery model as described in this project is that it is best suited for individual intervention sessions. Individual intervention sessions are not common in public school service delivery (ASHA, 2008). In addition, the telehealth services were provided in a room separate from the general education classroom. This pull-out model can increase the difficulty of collaborating with classroom teachers, and relating intervention to current classroom curriculum. These challenges can be minimized by developing collaboration through e-mail, designated faculty video conferencing sessions, and utilizing the e-helper to gather needed information. Despite these difficulties, we maintain that further research in using telehealth to deliver school based speech/language intervention services is warranted. The reasons include: (1) telehealth intervention appears to be effective in accomplishing IEP goals and objectives; (2) failure to provide children with access to adequate speech/ language intervention services could violate their rights to a free and appropriate public education, and; (3) the telehealth delivery model can likely be implemented in school districts that meet reasonable conditions such as a quiet room available for delivery of services, the support of an informational technology employee, a dedicated computer, web camera, and headset, and a telehealth assistant or aide to provide support services for the project.

Numerous recommendations for future research emerge from this study. First, the current study was conducted with a readily available sample of students selected from an identified population of students with communication impairments. It was designed to assess student progress within a typical school-based intervention program using typical progress monitoring measures. Conducting research in non-laboratory, clinical settings facilitates evidence-based practice by bridging the gap between research and clinical practice (Justice \& Fey, 2004). However when conducting non-laboratory research, some independent variables could not be controlled. For example, several different SLPs provided the assessment of the communication disorders, and developed the IEP goals and objectives for each student. Also, the SLPs had varying amounts of experience. It is important to replicate the study and to continue to accumulate evidence regarding the use of telehealth for the provision of speech/language intervention for schoolage children. Additional research in a laboratory setting can control for these types of variables. Forthcoming studies should recruit students matched on important characteristics who could then be randomly assigned to a telehealth or side-by-side condition.

Speech and language intervention delivered by telehealth is an emerging service delivery model in the public school setting. Additional areas of study include: (1) the reliability of assessing speech and language impairments via telehealth; (2) comparing specific intervention programs or methods in telehealth vs. traditional service delivery models; (3) investigating various videoconferencing software and hardware in the provision of services; (4) identifying the ages of students and the types of communication disabilities that can be adequately serviced via telehealth; and (5) implementing telehealth speech-language intervention within the regular education classroom. Based on the results of this initial investigation, live interactive video conferencing appears to be a viable service delivery model for school-age children who receive speech sound intervention services in the public schools. This alternative delivery model may be utilized to provide needed intervention services to rural school districts that do not have adequate speech-language intervention services available to them. Additional research will help to refine the best uses of this technology for children with communication impairments. 


\section{ACKNOWLEDGEMENTS}

This research was funded by a grant from the Ohio Department of Education through the OMNIE project. TinyEye technologies extended a research discount on the subscription price of the TinyEYE Speech Therapy Software (Sutton \& Brick, 2005).

\section{REFERENCES}

1. American Speech-Language-Hearing Association (2008). National Outcomes Measurement Scales K- 12 2008 National Data Report. Retrieved June 24, 2009 from www.asha.org.

2. American Speech-Language-Hearing Association. (2005). Speech-language pathologists providing clinical services via telepractice: position statement [position statement]. Available from http://www.asha. org/docs/ html/PS2005-00116.html

3. Boswell, S. (2007, March 6). Ohio grant addresses personnel shortage: Innovative strategies meet shortand long-term goals. The ASHA Leader, 2 (3)1, 14-15.

4. Christmann, E. \& Badgett, J. (2003). A meta-analytic comparison of the effects of computer-assisted instruction on elementary students' academic achievement. Information Technology in Childhood Education Annual, 91-104.

5. Forducey, P. (2006, August 15). Speech telepractice program expands options for rural Oklahoma schools. The ASHA Leader, 11(10), 12-13.

6. Gierut, J. (1998). Treatment efficacy: Functional phonological disorders in children. Journal of Speech and Hearing Research, 41, s85-s100.

7. Goldman, R. \& Fristoe, M. (2002). The GoldmanFristoe Test of Articulation-2. Minneapolis, MN: American Guidance Service Inc.

8. Grogan-Johnson, S., Alvares, R., Rowan, L.E. \& Creaghead, N. (2010). A pilot study comparing the effectiveness of speech-language intervention provided by telehealth and traditional side-by-side intervention. Journal of Telemedicine and Telecare, 16(3), 134-139.

9. Individuals with Disabilities Education Act. (2004). Section 800 [c]8. Retrieved July 8, 2009, from http:// idea.ed.gov.

10. Justice, L.M., \& Fey, M.E. (2004, September 21). Evidence-based practice in schools: Integrating craft and Theory with science and data. The ASHA Leader. Retrieved February 15, 2011 from http://www. asha.org/Publications/leader/2004/040921/f040921a. htm.

11. Lewis, C., Packman, A., Onslow, M., Simpson, J., \& Jones, M. (2008). A phase II trial of telehealth delivery of the Lidcombe Program of early Stuttering Intervention. American Journal of Speech- Language Pathology, 17, 139-149.

12. Madsen, L., \& Shellsey, R. (2005, November). Using teleintervention to address the slp shortage in North Dakota. Paper presented at the annual convention of the American Speech Language Hearing Association Convention, San Diego, CA.

13. Masterson, J. (1995). Future directions in computer use. Language, Speech and Hearing Services in Schools, 26, 260-262. 
14. McGuire, R. (1995). Computer based instrumentation: Issues in clinical applications. Language, Speech and Hearing Services in Schools, 26, 223-231.

15. Polovoy, C. (2008, July 15). Telepractice in schools helps address personnel shortages. The ASHA Leader, 13(9), 22-24.

16. Ruscello, D., Yanero, D., \& Ghalichebaf, M. (1995). Cooperative service delivery between a university clinic and a school system. Language, Speech and Hearing Services in Schools, 26, 273- 277.

17. Shriberg, L., Kwiatkowski, J., \& Snyder, T. (1989). Tabletop versus microcomputer-assisted speech management: Stabilization phase. Journal of Speech and Hearing Disorders, 54, 233-248.

18. Shriberg, L., Kwiatkowski, J., \& Snyder, T. (1990). Tabletop versus microcomputer- assisted speech management: Response evocation phase. Journal of Speech and Hearing Disorders, 55, 635-655.

19. Secord, W. (1989). The traditional approach to treatment. In N.A.Creaghead, P.W.Newman \& W.A. Secord (Eds.), Assessment and Remediation of Articulation and Phonological Disorders, second edition, (pp.129-157). Columbus, OH:Merrill Publishing Company.

20.Semel, E., Wiig, E., \& Secord, D. (2003). Clinical Evaluation of Language Fundamentals-4th Edition. San Antonio, Texas: Pearson.

21. Sutton, G., \& Brick, M. (2005). TinyEye Online Speech Therapy [computer software]. Saskatoon, Saskatchewan, Canada: TinyEYE Therapy Services.

22. VanDusen, L., \& Worthern, B. (1995). Can integrated instructional technology transform the classroom? Educational Leadership, 53, 28-33.

23. Waite, M., Cahill, L., Theodoros, D., Busuttin, S., \& Russell, T. (2006). A pilot study of online assessment of childhood speech disorders. Journal of Telemedicine and Telecare, 12 (Suppl.3), 92-24.

24. Waite, M., Theodoros, D., Russell, T., \& Cahill, L (2010). Internet-based telehealth assessment of language using the CELF-4. Language-SpeechHearing Services in Schools, 41, 445-458. 
